\title{
Article
}

Arq Neuropsiquiatr 2011;69(6):924-927

\section{Risk and determinant factors for obstructive sleep apnea in patients with epilepsy}

\author{
Monique Venturi ${ }^{1}$, Gisele Schenkel Leite Moura Neves², \\ Igor Monteiro Pontes ${ }^{3}$, Andre Valois ${ }^{3}$, Marleide da Mota Gomes ${ }^{4}$
}

\begin{abstract}
Objective: To evaluate the prevalence of risk of having obstructive sleep apnea (OSA) and its determinants in patients with epilepsy (PE). Method: 98 adult PE were prospectively screened for risk of OSA by Berlin questionnaire. Data was also collected about excessive daytime sleepiness, depression, anxiety, clinical and socio-demographic characteristics. Results: The PE main characteristics: 59-men/39-women, mean age $=39.97, \mathrm{SD}=12.3$, range 18-66. The prevalence of the risk of OSA was $55.1 \%(\mathrm{Cl} 95 \%, 0.45-0.65)$. The high risk for OSA was related with body mass index (BMI) $(p=0.000)$, neck circumference (NC) $(p=0.000)$, arterial hypertension (AH) $(p=0.000)$, and anxiety $(p=0.006)$, without relationship with number of seizures, number of antiepileptic drugs, age or depression. The NC was statistically significant regarding risk of OSA, mainly in men. Conclusion: We found a high risk of OSA in this sample. The main implicated measures were the large NC, high BMI and anxiety. The anthropometric variables were more relevant than those related to epilepsy itself and similar to those of the general population.
\end{abstract}

Key words: obstructive sleep apnea, epilepsy, obesity.

Risco e determinantes para apneia obstrutiva do sono em pacientes com epilepsia

\section{RESUMO}

Objetivo: Avaliar riscos e fatores determinantes para síndrome da apneia obstrutiva do sono (SAOS) em pacientes com epilepsia (PCE). Método: 98 PCE adultos foram avaliados prospectivamente para risco de SAOS pelo questionário Clínico de Berlim, e também para sonolência excessiva diurna, depressão, ansiedade, características socioeconômico e demográficas. Resultados: 98 PCE foram estudados (59-homens / 39-mulheres, idade média $=39,97, \mathrm{DP}=12,3,18-66$ anos). A prevalência de risco para SAOS foi de $55,1 \%(\mathrm{Cl}$ $95 \%, 0,45-0,65)$. O alto risco de SAOS estava relacionado com índice de massa corporal (IMC) $(p=0,000)$, circunferência do pescoço (CP) $(p=0,000)$, hipertensão arterial $(p=0,000)$ e ansiedade $(p=0,006)$, sem relação com número de crises, drogas antiepiléptica, idade ou depressão. A CP foi estatisticamente significativa na relação com SAOS, principalmente em homens. Conclusão: Encontrou-se alta prevalência de risco de SAOS nesta população. As medidas mais relevantes foram CP principalmente em homens, IMC e ansiedade. As variáveis antropométricas foram mais importantes que aquelas relacionadas à própria epilepsia, o que foi similar à população em geral.

Palavras-Chave: síndrome de apneia obstrutiva do sono, epilepsia, obesidade.

\section{Correspondence}

Marleide da Mota Gomes

Programa de Epilepsia do Instituto de Neurologia Deolindo Couto / UFRJ

Av. Venceslau Braz 95

22290-140 Rio de Janeiro RJ - Brasil

E-mail: mmotagomes@acd.ufrj.br

Received 3 March 2011

Received in final form 6 July 2011

Accepted 13 July 2011
Obstructive sleep apnea (OSA) and epilepsy are conditions that can be interrelated ${ }^{1}$. The prevalence of OSA in the general adult population in USA (ages 30 to
60 ) is $24 \%$ in men, and $9 \%$ in women according to Chihorek et al. ${ }^{2}$. The literature reports that in older adults with epilepsy the presence of OSA is associated with sei-

${ }^{1}$ Fellow, Post-Graduate Program of the Institute of Psychiatry, Universidade Federal do Rio de Janeiro (UFRJ), Rio de Janeiro RJ, Brazil; ${ }^{2}$ Neurologist, Institute of Neurology, UFRJ; ${ }^{3}$ Undergraduate Students, Faculty of Medicine, UFRJ; ${ }^{4}$ Associate Professor, Faculty of Medicine, Institute of Neurology, UFRJ. 
zure frequency worsening or late onset seizures ${ }^{2}$. Hollinger et $\mathrm{al}^{3}$, are the unique authors that related a possible temporal relationship between onset of OSA symptoms and change in seizure control in about two thirds of their patients. The same authors considered that the change in seizure control is shown by increase in seizure frequency, first onset of seizures or new onset of status epilepticus. In this way, several case series have shown that the treatment of OSA may reduce seizures frequency, and lessen daytime sleepiness in adults ${ }^{1}$. Manni et al. ${ }^{4}$, indicated that the risk factors for OSA are the same in epilepsy subjects as in the general population. Untreated OSA is associated with a variety of potentially life-threatening conditions including cardiac arrhythmias, arterial hypertension (HA), stroke and myocardial infarction ${ }^{5}$. Regarding the potential importance of the relationship between OSA and epilepsy, the main goal of this paper is to evaluate the prevalence of the risk of OSA in this studied population, and its risk factors (clinical and anthropometrical characteristics, anxiety and depression symptomatology).

\section{METHOD}

This is a cross-sectional study based on 98 unselected patient population that were under the care in the Neurology Institute of Rio de Janeiro, all of them fulfilling the eligibility criteria. Patients agreeing to sign an informed consent form were included in the study "The Sleep disorders in adult patients with epilepsy: study of prevalence, quality of sleep and life", approved by the Ethics Committee of the Institute of Neurology of the Federal University of Rio de Janeiro. This elicits comprehensive subjective clinical information about sleep from individuals with diagnosis of epilepsy. The auto-applied questionnaires were answered by the patients before the medical consultation. For the purpose of studying the specific topic about risk of OSA in this population, data was collected about: [1] socio-demographic and clinical characteristics; [2] risk of OSA by means of Berlin clinical questionnaire (which was the dependent variable); [3] anxiety and depression symptoms by means of the Beck's Inventories ${ }^{6}$; [4] excessive daytime sleepiness (EDS) by means of the Epworth scale. Berlin questionnaire has three categories: $1^{\text {st }}$ with five questions about snoring: $2^{\text {nd }}$ with four about daytime somnolence: $3^{\text {rd }}$ with 1 question about high blood pressure. High risk for OSA is considered if two or more categories are positive ${ }^{7,8}$. The cut-off points for neck circumference $(\mathrm{NC})$ regarding gender was based on Onat et al. ${ }^{9}$.

The data were analyzed using the statistical package for social sciences (SPSS 11.01). The Mann-Whitney Utest, Spearman's rank correlation coefficient and Pearson's chi-square tests were applied. All statistical tests were two-tailed, and p values less than 0.05 were considered significant.

\section{RESULTS}

There were 98 patients composed of 39 women and 59 men, whose mean age was of 39.97, $\mathrm{SD}=12.3$, range 18-66. In the studied population, the risk of OSA was $55.1 \%$ (CI 95\%, 0.45-0.65). More than half of the studied patients were overweight, and $28.9 \%$ has more than 5 seizures/ year (Table 1). High risk for OSA was related with body mass index (BMI) $(\mathrm{p}=0.000)$, neck circumference $(\mathrm{NC})$ $(\mathrm{p}=0.000), \mathrm{AH}(\mathrm{p}=0.000)$ and anxiety score $(\mathrm{p}=0.006)$, without relationship with number of seizures, number of antiepileptic drugs used, age or depression symptoms (Table 2 and 3). The NC was statistically significant to OSA, mainly in men ( $\mathrm{p}=0.000)$ (Table 2 and 3). Regarding the relationship analysis between the Berlin questionnaire components and clinical characteristics, we observe significative relationship between EDS and snore $(\mathrm{p}=0.010)$, and between AH and BMI ( $\mathrm{p}=0.000)$ (Table 4).

Table 1. Main characteristics of the studied population.

\begin{tabular}{|c|c|c|c|c|}
\hline Variables & Cathegories & $n$ & $\%$ & Mean (SD) \\
\hline \multirow[t]{2}{*}{ Gender } & Masculine & 59 & 60.2 & - \\
\hline & Feminine & 39 & 39.8 & \\
\hline \multirow[t]{2}{*}{ Age } & $<40$ & 49 & 50 & $39.97(12.3)$ \\
\hline & $\geq 40$ & 49 & 50 & \\
\hline \multirow[t]{2}{*}{ Epilepsy type } & Focal & 37 & 37.8 & - \\
\hline & Generalized & 60 & 61.2 & \\
\hline \multirow{2}{*}{$\begin{array}{l}\text { Seizure } \\
\text { frequency / year }\end{array}$} & $<6$ & 68 & 70.1 & $17.12(55.57)^{*}$ \\
\hline & $\geq 6$ & 28 & 28.9 & \\
\hline \multirow[t]{2}{*}{ AED number } & $<2$ & 47 & 48.5 & $1.63(0.697)$ \\
\hline & $\geq 2$ & 50 & 51.5 & \\
\hline \multirow[t]{2}{*}{ BMI } & $\begin{array}{l}\text { Not overweight } \\
\text { or obese }\end{array}$ & 46 & 47 & $25.79(4.847)$ \\
\hline & $\begin{array}{l}\text { Overweight } \\
\text { or obese }\end{array}$ & 50 & 51.3 & \\
\hline \multirow[t]{2}{*}{ Female NC } & $<35 \mathrm{~cm}$ & 23 & 5 & $33.71(6.20)$ \\
\hline & $\geq 35 \mathrm{~cm}$ & 14 & 35.9 & \\
\hline \multirow[t]{2}{*}{ Male NC } & $<39 \mathrm{~cm}$ & 25 & 43.1 & $34.41(3.00)$ \\
\hline & $\geq 39 \mathrm{~cm}$ & 33 & 56.9 & \\
\hline \multirow{2}{*}{$\begin{array}{l}\text { Risk of OSA (Berlin } \\
\text { questionnaire) }\end{array}$} & Low & 44 & 44.9 & - \\
\hline & High & 54 & 55.1 & \\
\hline \multirow[t]{2}{*}{ EDS (Epworth) } & $<11$ & 51 & 52 & $10.11(5.48)$ \\
\hline & $\geq 11$ & 46 & 46.9 & \\
\hline
\end{tabular}

AED: antiepileptic drugs; BMI: body mass index; NC: neck circumference; EDS: excessive daytime sleepiness; OSA: obstructive sleep apnea; * outlier with more than 1000 seizures/year; SD: standard deviation. 
Table 2. Characteristics of patients with low risk and high risk according to the Berlin questionnaire.

\begin{tabular}{lccc}
\hline & & Berlin & \\
\cline { 2 - 3 } Variable & Low N (Mean-SD) & High N (Mean-SD) & p value \\
\hline Age & $44(38.32-12.15)$ & $54(41.31-12.43)$ & 0.233 \\
Seizures frequency / year & $44(34.70-163.32)$ & $53(22.58-70.84)$ & 0.627 \\
AED's number & $44(1.68-0.71)$ & $54(1.59-0.69)$ & 0.530 \\
BMI & $43(23.48-3.29)$ & $54(27.62-5.12)$ & 0.000 \\
NC male & $42(35.00-6.35)$ & $53(38.93-3.44)$ & 0.000 \\
NC female & $43(8.53-0.91)$ & $54(11.37-0.65)$ & 0.074 \\
Depression (Beck Inventory) & $43(9.70-11.09)$ & $54(13.69-11.80)$ & 0.514 \\
Anxiety (Beck Inventory) & $43(9.05-9.07)$ & $54(15.31-12.17)$ & 0.006 \\
\hline
\end{tabular}

AED: antiepileptic drugs; BMI: body mass index; NC: neck circumference; SD: standard deviation.

Table 3. Relationship between dichotomized important variables and obstructive sleep apnea risk.

\begin{tabular}{|c|c|c|c|c|c|c|}
\hline \multirow[b]{3}{*}{ Variables } & \multirow[b]{3}{*}{ Cathegories } & \multicolumn{4}{|c|}{ Berlin } & \multirow[b]{3}{*}{$\mathrm{p}$ value } \\
\hline & & \multicolumn{2}{|c|}{ Low } & \multicolumn{2}{|c|}{ High } & \\
\hline & & $\mathrm{n}$ & $\%$ & $\mathrm{n}$ & $\%$ & \\
\hline \multirow[t]{2}{*}{$\mathrm{BMI}$} & Not overweight or obese & 29 & 29.6 & 18 & 18.4 & 0.001 \\
\hline & Overweight or obese & 14 & 14.3 & 36 & 36.7 & \\
\hline \multirow[t]{2}{*}{$\mathrm{AH}$} & No & 40 & 39 & 23 & 22.5 & 0.000 \\
\hline & Yes & 2 & 2 & 31 & 30.4 & \\
\hline \multirow[t]{2}{*}{ NC Female } & $<35 \mathrm{~cm}$ & 15 & 38.4 & 5 & 12.8 & 0.034 \\
\hline & $\geq 35 \mathrm{~cm}$ & 6 & 15.4 & 11 & 28.2 & \\
\hline \multirow[t]{2}{*}{ NC Male } & $<39 \mathrm{~cm}$ & 14 & 24 & 11 & 19 & 0.013 \\
\hline & $\geq 39 \mathrm{~cm}$ & 7 & 12 & 26 & 44 & \\
\hline
\end{tabular}

BMI: body mass index; AH: arterial hypertension; NC: neck circumference.

Table 4. Relationship between the Berlin questionnaire components and clinical characteristics.

\begin{tabular}{|c|c|c|c|c|c|c|c|c|c|c|}
\hline \multirow[b]{3}{*}{ Variables } & \multirow[b]{3}{*}{ Cathegories } & \multicolumn{9}{|c|}{ Berlin questionnaire components } \\
\hline & & \multicolumn{3}{|c|}{ Snore } & \multicolumn{3}{|c|}{ Sleepiness } & \multicolumn{3}{|c|}{$\mathrm{AH}$} \\
\hline & & Yes & No & $\mathrm{p}$ & Yes & No & $\mathrm{p}$ & Yes & No & $\mathrm{p}$ \\
\hline \multirow[t]{2}{*}{ Gender } & Masculine & 43 & 16 & 0.126 & 32 & 27 & 1.000 & 22 & 37 & \\
\hline & Feminine & 22 & 17 & & 21 & 18 & & 11 & 26 & 0.161 \\
\hline \multirow[t]{2}{*}{ Age } & $<40$ & 29 & 20 & 0.199 & 27 & 22 & 1.000 & 13 & 36 & 0.092 \\
\hline & $\geq 40$ & 36 & 13 & & 26 & 23 & & 20 & 27 & \\
\hline \multirow[t]{2}{*}{ EDS (Epworth) } & $<11$ & 28 & 23 & 0.010 & 28 & 23 & 1.000 & 15 & 35 & 0.407 \\
\hline & $\geq 11$ & 37 & 9 & & 25 & 21 & & 18 & 28 & \\
\hline \multirow[t]{2}{*}{ Epilepsy type } & Focal & 18 & 19 & 0.014 & 19 & 18 & 0.612 & 8 & 28 & 0.242 \\
\hline & Generalized & 46 & 14 & & 33 & 27 & & 24 & 35 & \\
\hline \multirow[t]{2}{*}{ Seizures frequency / year } & $<6$ & 45 & 23 & 1.000 & 37 & 31 & 0.828 & 25 & 42 & 0.590 \\
\hline & $\geq 6$ & 19 & 10 & & 15 & 14 & & 8 & 20 & \\
\hline \multirow[t]{2}{*}{ AED number } & $<2$ & 29 & 18 & 0.397 & 29 & 18 & 0.161 & 16 & 31 & 0.389 \\
\hline & $\geq 2$ & 36 & 15 & & 24 & 27 & & 17 & 32 & \\
\hline \multirow[t]{2}{*}{ BMI } & Underweight or normal & 26 & 21 & 0.071 & 23 & 24 & 0.141 & 37 & 39 & 0.000 \\
\hline & Pre obese or obese & 38 & 12 & & 30 & 20 & & 26 & 23 & \\
\hline
\end{tabular}

AED: antiepileptic drugs; BMI: body mass index; NC: neck circumference; AH: arterial hypertension; EDS: excessive daytime sleepiness. 


\section{DISCUSSION}

A high prevalence of risk to OSA was found in the studied population. It was similar to a Brazilian study carried out by Tufik et al. ${ }^{10}$ about the general population in São Paulo, where it was found $32.8 \%$ of prevalence of OSA diagnosed by polysomnography. The authors justified the results regarding their population that presents high age, obesity, and, also, using the criteria of the most recent International Classification of Sleep Disorders (ICDS-2) from American Academy of Sleep Medicine and more sensitive polysomnography's canula evaluation ${ }^{10,11}$.

In another study using Berlin questionnaire, also in a Brazilian setting, the authors found high risk of OSA: 78\% in cases with resistant $\mathrm{AH}$ vs. $48 \%$ in those with controlled $\mathrm{AH}$. It is also important to remember that $\mathrm{AH}$ is one component of Berlin questionnaire and, consequently, in a setting of high prevalence of $\mathrm{AH}$, like in Brazil, the rate of high risk for OSA by the Berlin questionnaire can be overestimated. This questionnaire ranges from $68 \%$ to $86 \%$ of sensitivity, and $49 \%$ to $77 \%$ of specificity as mentioned by Friedman et al. ${ }^{12}$ which can overestimate the risk to OSA, even more in a setting like ours, as already mentioned.

The main risk factors for OSA were partially similar in our study when compared to the literature ${ }^{1-3}$. It was expected that the number of seizures, the number of antiepileptic drugs used (meaning pharmacoresistant epilepsy), age and depression score were proportionally related to high risk of $\mathrm{OSA}^{1-3}$ but we did not find this relations statistically significant in our study. Maybe because only $1 / 3$ of the studied sample has more than 5 seizures / year, which would make necessary studying a larger sample size.

The strongest relationship is with anthropometric risk factors, as seen in most of the studies ${ }^{4,5,9-13}$. Therefore, the main measures that we found were the EDS, the large NC mainly in men, and the high BMI that are related to obesity. Deegan and McNicholas ${ }^{13}$ said that in male patients according to age, abdominal girth was a closer correlate with apnea-hipopnea index (AHI) than NC and BMI, but, in the other hand, the $\mathrm{NC}$ was the best correlate of $\mathrm{AHI}$ in female patients, suggesting a possible sex difference in fat distribution and its effect on AHI. In the same article the authors affirm that BMI was a significant independent that correlates with $\mathrm{AHI}$ on multiple linear regression analysis while $\mathrm{NC}$ was not. However, in our study both the NC (especially $\mathrm{NC}$ from male patients) and BMI were strongly correlated to the high risk to OSA as demonstrated in Table 2 and 3.

Another point is the fact that patients that slept predominantly on their back were found to be at increased risk of having OSA. In another study, Lambert et al, payed attention to the development of OSA, the rapid weight gain, following treatment with antiepileptic drugs, especially vigabatrin. In spite of the rare link between epilepsy, namely, central apnea, as cause to OSA, Dominici et al. ${ }^{14}$ presented a case of central and obstructive sleep apnea due to epileptic seizures and report that this condition may be neglected in most instances. In this way the authors suggested also the video-EEG-polysomnography to respiratory events associated to seizures.

Furthermore, it is shown in our study the significant relation between anxiety and risk of OSA. In this context, the psychiatric comorbidities can be consequence or the cause of OSA, and then we have a complex mechanism to be understood in each case. Consequently, it is necessary a good knowledge and control of all these associated comorbidities.

There are many determinant factors for OSA being studied at the moment as BMI and NC for example and certainly these findings can help epileptic and non epileptic patients, mainly the overweight ones. Therefore, the comorbidities and the seizures can be avoided or lessened by the correct management of these variables. Weight loss, dietary advice, bariatric surgery and alcohol consumption reduction are important measures to decrease OSA and its consequences, such as hypertension. Besides, larger longitudinal studies with the use of polysomnography appear warranted to study more thoroughly our Brazilian population with epilepsy.

\section{REFERENCES}

1. Venturi M, Valois A, Pontes IM, Gomes MM. Relação da epilepsia com a síndrome de apneia obstrutiva do sono: revisão. J Epilepsy Clin Neurophysiol 2010;16:18-22.

2. Chihorek AM, Abou-Khalil B, Malow BA. Obstructive sleep apnea is associated with seizure occurrence in older adults with epilepsy. Neurology 2007;69:1823-1827.

3. Hollinger P, Khatami R, Gugger M, Hess CW, Bassetti CL. Epilepsy and obstructive sleep apnea. Eur Neurol 2006;55:74-79.

4. Manni R, Terzaghi M, Arbasino C, Sartori I, Galimberti CA, Tartara A. Obstructive sleep apnea in a clinical series of adult epilepsy patients: frequency and features of the comorbidity. Epilepsia 2003;44:836-840.

5. Lambert MV, Bird JM. Obstructive sleep apnea following rapid weight gain secondary to treatment with vigabatrin (Sabril). Seizure 1997;6:233-235.

6. Gorestein C, Andrade L. Inventário de depressão de Beck: propriedades psicométricas da versão em português. Rev Psiquiatr Clin 1998;25:245-250

7. Bertolazi AN, Fagondes SC, Hoff LS, Pedro VD, Menna Barreto SS, Johns MW.Portuguese-language version of the Epworth sleepiness scale: validation for use in Brazil. J Bras Pneumol 2009;35:877-883.

8. Netzer NC, Stoohs RA, Netzer CM, Clark K, Strohl KP. Using the Berlin questionnaire to identify patients at risk for the sleep apnea syndrome. Ann Intern Med 1999;131:485-491.

9. Onat A, Hergenc, YuKsel H, et al. Neck circumference as a measure of central obesity: associations with metabolic syndrome and obstructive sleep apnea syndrome beyond waist circumference. Clin Nutr 2009;28:46-51.

10. Tufik S, Santos-Silva R, Taddei JA, Bittencourt LRA. Obstructive sleep apnea syndrome in the São Paulo Epidemiologic Sleep Study. Sleep Med 2010; 11:441-446.

11. Gus M, Gonçalves SC, Martinez D, et al. Risk for obstructive sleep apnea by berlin questionnaire, but not daytime sleepiness, is associated with resistant hypertension: a case-control study. Am J Hypertens 2008;21:832-835.

12. Friedman M, Wilson MN, Pulver T, et al. Screening for obstructive sleep apnea/hypopnea syndrome: subjective and objective factors. Otolaryngol Head Neck Surg 2010;142:531-535.

13. Deegan PC, McNicholas WT. Predictive value of clinical features for the obstructive sleep apnoea syndrome. Eur Respir J 1996;9:117-124.

14. Dominici M, Pompeu Filho F, Gomes MM. Probable causal link between epilepsy and sleep apnea: case report. Arq Neuropsiquiatr 2007;65: 164-166. 